\title{
Pharmacokinetics and biodistribution of a novel anticancer thyrointegrin av $\beta 3$ antagonist: triazole modified tetraiodothyroacetic acid conjugated to polyethylene glycol (P-bi-TAT)
}

\author{
Kazutoshi Fujioka, Kavitha Godugu and Shaker A. Mousa* (D)
}

\begin{abstract}
We previously developed a triazole modified tetraiodothyroacetic acid (TAT) conjugated to a polyethylene glycol (PEG)-based thyrointegrin avß3 antagonist targeted compound, called P-bi-TAT. It exhibited potent anti-angiogenic and anticancer activities in vivo. The objective of the current study is to develop a quantitative bioanalytical method for P-bi-TAT using liquid chromatography-tandem mass spectrometry (LC-MS/MS) and to elucidate pharmacokinetics (PK) and biodistribution of P-bi-TAT in animals. We used in-source collision-induced dissociation (CID) for ionization of P-bi-TAT in the positive mode, followed by multiple reaction monitoring (MRM) for quantification. P-bi-TAT was quantified using P-mono-TAT as an internal standard because of its similarity in structure and physicochemical properties to P-bi-TAT. The LOQ for P-bi-TAT was $30 \mathrm{ng} / \mu \mathrm{L}$ and the recovery efficiency was 76\% with the developed method. Cmax and AUC results at different doses (1, 3, $10 \mathrm{mg} / \mathrm{kg}) \mathrm{in}$ rats suggest that P-bi-TAT is dose-dependent within the range administered. Results for Cmax and AUC in monkeys at a low dose $(25 \mathrm{mg} / \mathrm{kg}$ ) were comparable to those in rats. Biodistribution of subcutaneously administered P-bi-TAT in the brain of rats ranged from 7.90 to $88.7 \mathrm{ng} / \mathrm{g}$ brain weight, and levels of P-bi-TAT in the brain were dosedependent. The results suggest that P-bi-TAT is a potential candidate as a molecular-targeted anticancer therapeutic with blood-brain barrier permeability and acceptable PK parameters. Its accumulation in organs, toxicokinetic, and pharmacodynamics needs to be further investigated.
\end{abstract}

Keywords: PEGylated, Triazole tetrac, Integrin avß3 antagonist, Pharmacokinetic, Toxicokinetic, LC-MS/MS, Antiangiogenic, Blood-brain barrier

\section{Introduction}

Cancer was the second leading cause of death in the USA in 2018, after heart disease (Xu et al. 2020). It is not a single disease but a variety of different cancer types including myeloma, thyroid, leukemia, esophagus, nonHodgkin lymphoma, stomach, and prostate cancer (Henley et al. 2020). Among cancers, brain cancer is

\footnotetext{
* Correspondence: shaker.mousa@acphs.edu

Pharmaceutical Research Institute, Albany College of Pharmacy and Health Sciences, 1 Discovery Drive, Rensselaer, NY 12144, USA
}

difficult to cure because of its poor prognosis, and the blood-brain barrier and blood tumor barrier that restrict the delivery of therapeutics (Fox et al. 2019). There are FDA-approved anticancer agents against brain cancers such as temozolomide; however, their efficacies are not enough to stop brain tumor progression beside their significant adverse effects (Anthony et al. 2019). Thus, more efficient, and safer anticancer therapeutics and improved drug delivery systems are under investigation in the pharmaceutical industry and in academia.

\section{Springer Open}

() The Author(s). 2021 Open Access This article is licensed under a Creative Commons Attribution 4.0 International License, which permits use, sharing, adaptation, distribution and reproduction in any medium or format, as long as you give appropriate credit to the original author(s) and the source, provide a link to the Creative Commons licence, and indicate if changes were made. The images or other third party material in this article are included in the article's Creative Commons licence, unless indicated otherwise in a credit line to the material. If material is not included in the article's Creative Commons licence and your intended use is not permitted by statutory regulation or exceeds the permitted use, you will need to obtain permission directly from the copyright holder. To view a copy of this licence, visit http://creativecommons.org/licenses/by/4.0/. 
Targeted anticancer drugs have been developed and applied to multiple cancer types, such as glioblastoma and neuroblastoma (Laquintana et al. 2009; Le Rhun et al. 2019; Maeda et al. 2016). Among them, nanoparticle-conjugated compounds show selective efficacy and potency to tumors via the enhanced permeability retention (EPR) effect (Maeda et al. 2016). We previously synthesized a conjugate of tetraiodothyroacetic acid (tetrac) and poly (lactic-co-glycolic acid) (PLGA) polymer, PLGA-diamino-propane-tetraiodothyroacetic acid (DAT), and nanoparticles of DAT (NDAT) showed high potency and efficacy on multiple cancers, such as glioblastoma and neuroblastoma (Lin et al. 2016; Lin et al. 2018; Sudha et al. 2017a). We then developed a conjugate of $\beta$-cyclodextrin with triazole-modifiedtetraiodothyroacetic acid (TAT), named $\beta$-C-TAT (CTAT). It showed anti-angiogenic in a chicken embryo chorioallantoic membrane (CAM) assay and anticancer activities in human primary GBM cells and in glioblastoma xenografted mice (unpublished data). Encouraged by the results, we then synthesized a polyethylene glycol (PEG)-based targeted drug, P-bi-TAT (1, Fig. 1), which is a conjugate of PEG4000 with two TAT moieties (Sudha et al. 2017b; Rajabi et al. 2019). It showed high affinity with a receptor on integrin $\alpha v \beta 3\left(\mathrm{IC}_{50} 0.14 \mathrm{nM}\right)$, anti-angiogenic activity in a CAM assay, and anticancer activities in human primary GBM cells and in glioblastoma xenografted mice $(10 \mathrm{mg} / \mathrm{kg}$ ) (Rajabi et al. 2019). In the current work, we developed a bioanalytical method for P-bi-TAT to determine its pharmacokinetics (PK) and biodistribution in experimental animals, i.e., rats and monkeys.

Liquid chromatography-tandem mass spectrometry (LC-MS/MS) is a gold standard for quantification of drug molecules. However, typical quadrupole-type mass spectrometers are not applicable for P-bi-TAT because its molecular weight is more than 3000 , and the quantification of high molecular weight PEGylated drug conjugates is a challenge by mass spectrometry. Yin et al. reported a quantitative method for PEGylated gemcitabine ( $\mathrm{Mw} 70-76 \mathrm{kDa}$ ) using LC-time of flight mass spectrometer (TOFMS) coupled with pre-

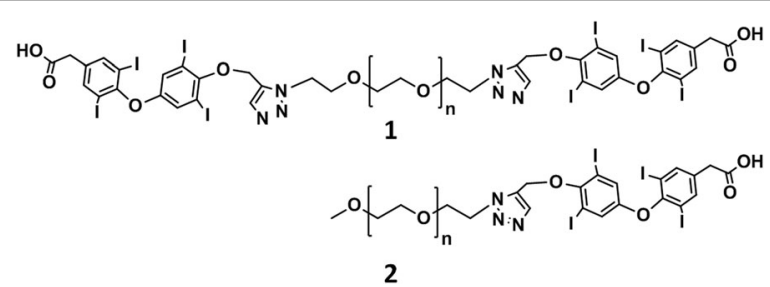

Fig. 1 Chemical structures of P-bi-TAT (1) and P-mono-TAT (2); and $n$ means the average number of repeating oxyethylene units (90) column derivatization and MS ${ }^{\text {ALL }}$ technique and applied to PK study of PEGylated gemcitabine in rats (Yin et al. 2020). In this study, we used in-source collision-induced dissociation (CID) for ionization of P-bi-TAT, followed by multiple reaction monitoring (MRM) (Warrack et al. 2013). P-mono-TAT (2, Fig. 1 ), which is another conjugate of PEG4000 with one TAT moiety, was used as an internal standard (IS) because its structure and physicochemical properties are similar to P-bi-TAT. We also optimized the extraction procedure from biological matrices using solid-phase extraction (SPE) with modification of the developed method for CTAT.

\section{Experimental \\ Materials \\ Chemicals and biologicals}

P-bi-TAT and P-mono-TAT were synthesized and purified in our laboratory. Acetonitrile, methanol, water, and formic acid were LC-MS grade and purchased from Sigma-Aldrich (St. Louis, MO). o-Phosphoric acid (85\%) was HPLC grade and purchased from Fisher Scientific (Pittsburgh, PA). Rat and monkey plasma were purchased from Bioreclamation IVT (New York, NY). Rats were purchased from Charles River (Kingston, NY).

\section{Methods}

\section{P-bi-TAT-treatment of rats and monkeys}

P-bi-TAT-treatment of rats was carried out in the animal facility of the Veterans Affairs (VA) Medical Center (Albany, NY), and the experimental protocol was approved by the Institutional Animal Care and Use Committee of the VA. Rats were housed under controlled conditions (temperature, $20-24{ }^{\circ} \mathrm{C}$; humidity, $60-70 \%$ ). Rats were allowed to acclimatize for at least 1 week prior to the start of treatments. For the PK study, P-bi-TAT (10 $\mathrm{mg} / \mathrm{kg}$ body weight) was administered subcutaneously to 4 rats, and plasma was collected at $0.25,0.5,1.5$, $3,6,12,24$, and $48 \mathrm{~h}$. Plasma samples were stored at $-80{ }^{\circ} \mathrm{C}$ for further analysis. For the biodistribution study, P-bi-TAT $(1,3,10 \mathrm{mg} / \mathrm{kg})$ was administered subcutaneously to 4 rats once a day for 3 weeks, and brain samples were collected $24 \mathrm{~h}$ after the last dose. Brain samples were stored at $-80{ }^{\circ} \mathrm{C}$ for further analysis.

The monkey study was conducted by a contract research organization. Briefly, P-bi-TAT (low dose, $25 \mathrm{mg} /$ $\mathrm{kg}$ body weight; high dose, $82.5 \mathrm{mg} / \mathrm{kg}$ ) was administered subcutaneously to male and female cynomolgus monkeys ( $n=2$ each) daily for 7 days, and plasma was collected at $0.5,2,6,10,16$, and $24 \mathrm{~h}$ on day 1 and day 7. Plasma samples were stored at $-80{ }^{\circ} \mathrm{C}$ for further analysis. 
Optimization of solid-phase extraction for sample preparation of P-bi-TAT in plasma

Fifty microliters of rat and monkey plasma with or without P-bi-TAT (150 ng/ $\mu \mathrm{L})$ and IS (P-mono-TAT, 150 $\mathrm{ng} / \mu \mathrm{L})$ was vortex-mixed with $100 \mu \mathrm{L} 4 \% \mathrm{H}_{3} \mathrm{PO}_{4}$ and loaded on a C18 or an OASIS HLB SPE column (Waters, Milford, MA) in triplicate, followed by washing with $1 \mathrm{~mL}$ of $5 \%$ methanol in water. P-bi-TAT and IS were eluted with $1 \mathrm{~mL}$ of acetonitrile, acetonitrile/water $(80 / 20 \mathrm{v} / \mathrm{v})$, acetonitrile/water $(50 / 50 \mathrm{v} / \mathrm{v})$, and acetonitrile/water $(20 / 80 \mathrm{v} / \mathrm{v})$. After centrifugation, solvent was evaporated under a nitrogen stream at $50{ }^{\circ} \mathrm{C}$. Extracts were reconstituted with $50 \mu \mathrm{L}$ of acetonitrile/ water $(80 / 20 \mathrm{v} / \mathrm{v})$.

Sample preparation of plasma with solid-phase extraction Fifty microliters of rat and monkey plasma with or without P-bi-TAT $(150 \mathrm{ng} / \mu \mathrm{L})$ and IS (P-mono-TAT, 150 $\mathrm{ng} / \mu \mathrm{L})$ was vortex-mixed with $100 \mu \mathrm{L} 4 \% \mathrm{H}_{3} \mathrm{PO}_{4}$ and loaded on an OASIS HLB SPE column (Waters, Milford, MA), followed by washing with $1 \mathrm{~mL}$ of $5 \%$ methanol in water. P-bi-TAT and IS were eluted with $1 \mathrm{~mL}$ of acetonitrile/water $(80 / 20 \mathrm{v} / \mathrm{v})$. After centrifugation, solvent was evaporated under a nitrogen stream at $50{ }^{\circ} \mathrm{C}$. Extracts were reconstituted with $50 \mu \mathrm{L}$ of acetonitrile/ water $(80 / 20 \mathrm{v} / \mathrm{v})$.

\section{Sample preparation of brain homogenate with liquid- liquid extraction}

Brain samples were thawed, weighed, and homogenized with the same volume of ice-cold water with a hand homogenizer. Rat brain homogenate $(100 \mu \mathrm{L})$ with or without P-bi-TAT $(150 \mathrm{ng} / \mu \mathrm{L})$ and IS (P-mono-TAT, $150 \mathrm{ng} / \mu \mathrm{L}$ ) was vortex-mixed with $1 \mathrm{~mL}$ of acetonitrile/ water $(80 / 20 \mathrm{v} / \mathrm{v})$ for $30 \mathrm{~min}$. After centrifugation, solvent was evaporated under a nitrogen stream at $50{ }^{\circ} \mathrm{C}$. Extracts were reconstituted with $50 \mu \mathrm{L}$ of acetonitrile/ water $(80 / 20 \mathrm{v} / \mathrm{v})$.

\section{LC-MS/MS instrumentation}

An API-4000 mass spectrometer (Sciex, Framingham, MA) equipped with Shimadzu UPLC system (Kyoto, Japan) was used for LC-MS/MS analyses. A Kinetex 2.6 $\mu \mathrm{m}$ Biphenyl 100 LS column $(50 \times 2.1 \mathrm{~mm}$, Phenomenex, Torrance, CA) was used for reversed-phase separation. Mobile phases were (A) water containing $0.1 \%$ formic acid and 5\% acetonitrile and (B) acetonitrile with $0.1 \%$ formic acid. The flow rate was $0.5 \mathrm{~mL} / \mathrm{min}$ and the gradient was linear from $0 \%$ B for $1 \mathrm{~min}$ to $95 \%$ B for 5$7 \mathrm{~min}$. The column oven temperature was $40{ }^{\circ} \mathrm{C}$ and the injection volume was $5 \mu \mathrm{L}$. Electro-spray ionization (ESI) was used in positive MRM mode. Mass transitions for analytes were as follows: Q1/Q3, 1358.1/582.4 (P-biTAT); 1402.1/626.4 (IS). The operative parameters of the mass spectrometer were as follows: declustering potentials (DP), $130 \mathrm{~V}$; entrance potentials (EP), 10; collision energies $(\mathrm{CE}), 51 \mathrm{eV}$; collision cell exit potential (CXP), $18 \mathrm{~V}$; curtain gas (CUR), 30 psi; gas 1 (GS1, nebulizer gas) 30 psi; gas 2 (GS2, heater gas) 50 psi; ion spray voltage (IS), $5000 \mathrm{~V}$; temperature (TEM), $400{ }^{\circ} \mathrm{C}$; collision activate dissociation (CAD) gas, 10 psi; dwell time, $150 \mathrm{~ms}$. Nitrogen was used for the gases.

A standard curve was obtained using standard solutions of P-bi-TAT with concentrations of 10.24, 25.6, 64, 160, 400, and $1000 \mathrm{ng} / \mathrm{mL}$.

\section{Determination of recovery efficient and matrix effect}

Recovery efficient was calculated with the response of extracts from spiked plasma sample (sample) and blank plasma sample (blank) with spike after extract as follows:

Recovery efficient $(\%)=$ Response in sample/Response in blank $\times 100$

Similarly, matrix effect was calculated with the response of extracts from spiked plasma sample (sample) and standard solution (standard) as follows:

Matrix effect $(\%)=$ Response in sample/Response in standard $\times 100$

\section{Determination of limit of quantification (LOQ) and limit of quantification (LOD)}

Standard curve was obtained using standard solutions of $\beta$-C-TAT with IS. The limit of quantification (LOQ) and the limit of quantification (LOD) was determined using data of six injections of a standard solution (1000 ng/ $\mathrm{mL})$. LOQ and LOD were calculated using the standard deviations (SD) of signals for the analyte and the slope of linear regression curve as follows:

$$
\begin{aligned}
& \mathrm{LOQ}=10 \times \mathrm{SD} / \text { slope } \\
& \mathrm{LOD}=3 \times \mathrm{SD} / \text { slope }
\end{aligned}
$$

\section{Results}

\section{Development of bioanalytical method for P-bi-TAT}

The ionization of P-bi-TAT was studied in positive and negative modes. Deprotonated pseudo-molecular ions $[\mathrm{M}-2 \mathrm{H}]^{2-}$ of P-bi-TAT were detected in negative mode (Fig. 2). The mean difference in $\mathrm{m} / \mathrm{z}$ of ions is 22.0 , which is corresponding to the half of an ethylene oxide unit (44 DA). The calculated MW of P-bi-TAT using m/ $\mathrm{z}$ of deprotonated pseudo-molecular ions was consistent with the theoretical values and ranged from $4899.6(n=$ $74)$ to $5998.2(n=99)$. The mathematical mean MW of P-bi-TAT calculated with strong thirteen $\mathrm{m} / \mathrm{z}$ of deprotonated pseudo-molecular ions was 5736.0 and is close to the theoretical $\mathrm{Mw}$ of P-bi-TAT, 5620. The mass spectrum of P-bi-TAT in negative mode is useful for 

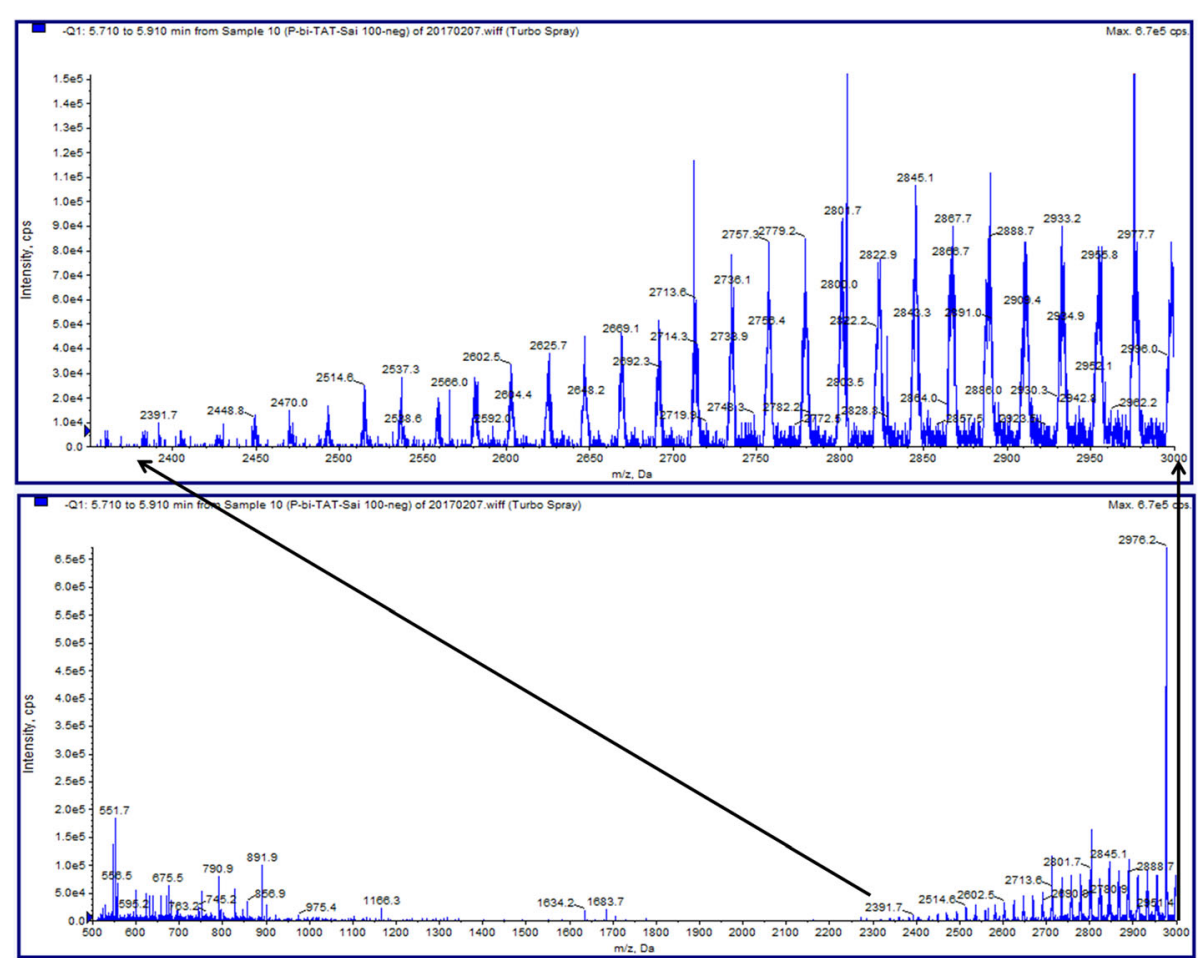

Fig. 2 Mass spectrum of P-bi-TAT in negative ESI scan mode

identification of the molecule; however, the intensities of deprotonated molecular ions $[\mathrm{M}-2 \mathrm{H}]^{2-}$ were very weak, so they were not applicable to MRM.

When positive mode was applied, multiply protonated pseudo-molecular ions and fragmental protonated molecular ions $[\mathrm{MH}]^{+}$of P-bi-TAT were detected by insource CID (Fig. 3). The calculated MW of P-bi-TAT using $\mathrm{m} / \mathrm{z}$ of multiply protonated pseudo-molecular ions $(z=5)$ was consistent with the theoretical values and ranged from $5077.0(n=78)$ to $6130.0(n=102)$. The mathematical mean MW of P-bi-TAT calculated with strong thirteen $\mathrm{m} / \mathrm{z}$ of deprotonated pseudo-molecular ions was 5605.3 and is close to the theoretical $\mathrm{Mw}$ of $\mathrm{P}$ bi-TAT, 5620. The region 1 of mass spectrum of P-biTAT in positive mode is useful for identification of the molecule; however, the intensities of multiply protonated molecular ions $[\mathrm{M}+\mathrm{nH}]^{\mathrm{n}+}$ were weak, so they were not applicable to MRM.

Next, DP was increased from $45 \mathrm{~V}$ to $130 \mathrm{~V}$ to enhance in-source CID, fragmental protonated

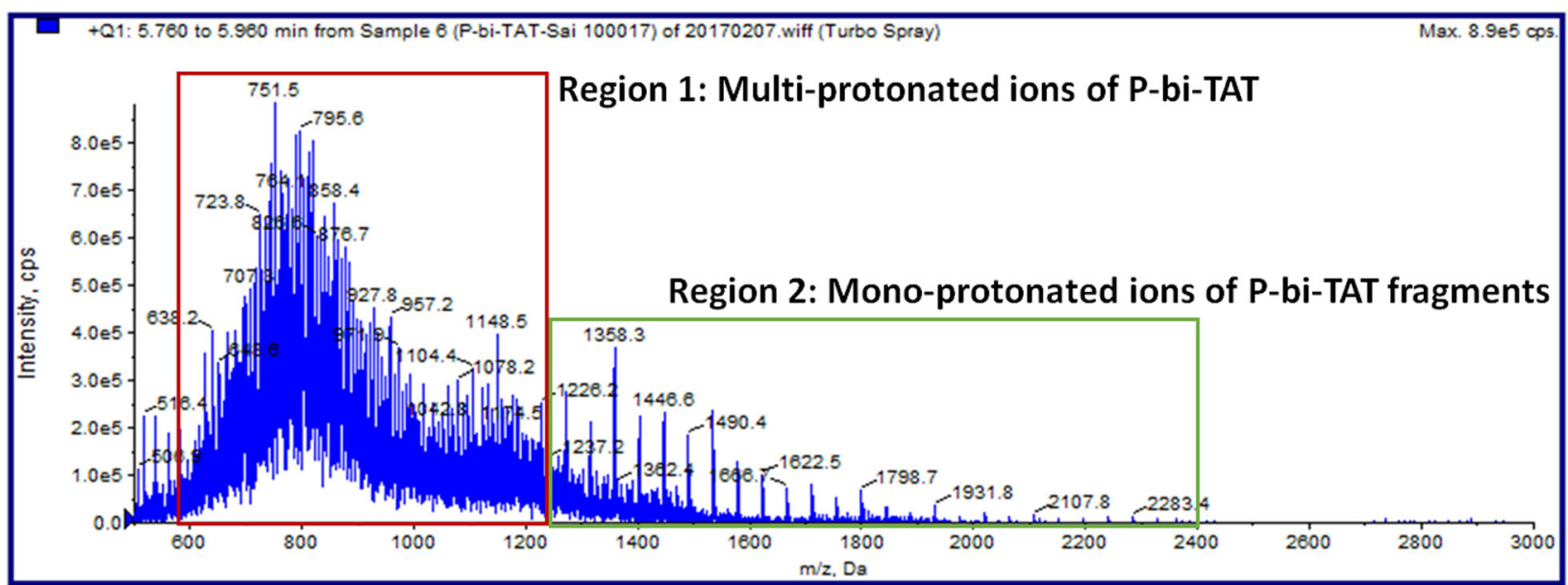

Fig. 3 Mass spectrum of P-bi-TAT in positive ESI scan mode 
molecular ions $[\mathrm{MH}]^{+}$of P-bi-TAT were dominantly detected (Fig. 4). The mean difference in $\mathrm{m} / \mathrm{z}$ of ions is 44.0 , which is equal to the ethylene oxide unit (44 da). The fragmental protonated ions ranged from $1182.1(n=8)$ to $2415.9(n=36)$. Two of the strong fragmental protonated ions $(\mathrm{m} / \mathrm{z} 1358,1402)$ were selected as precursor ions of MRM. MRM optimization was performed for each precursor ion, and MS parameters were optimized with flow injection analysis (FIA) optimization and an LC-MS/MS method was developed with the biphenyl column. The MRM was also applied to the IS because of the similarity in chemical structures of P-bi-TAT and IS. One of each MRM was used for quantification for Pbi-TAT and IS, and the other was used as a qualifier for each. Under these conditions, the retention times for P-bi-TAT and IS were 5.7 and $5.2 \mathrm{~min}$, respectively (Fig. 5).

The LC-MS/MS method for P-bi-TAT with IS was linear from a concentration of 25 to $1000 \mathrm{ng} / \mathrm{mL}$ (Fig. 6). The method detection limit (MDL) for P-biTAT was estimated to be $30 \mathrm{ng} / \mathrm{mL}$ under these conditions. Recovery efficiency was $76 \%$ and the matrix effect was $19 \%$.
PK and biodistribution of P-bi-TAT in rats and monkeys The bioanalytical method was applied to PK studies in rats and monkeys. The time course of P-bi-TAT levels in rat plasma (over $48 \mathrm{~h}$ ) is shown in Fig. 7 and in monkey plasma (on day 1 and day 7) in Fig. 8. Cmax and area under the curve (AUC) in rats and monkeys (day 1), PK parameters in rats and monkeys, and the dose proportionality ratios of Cmax and AUC are shown in Table 1.

Biodistribution of P-bi-TAT in the brain of rats varied from 7 (low) to 90 (high) ng/g brain weight (Fig. 9). The levels of P-bi-TAT in the brain were dose-dependent.

\section{Discussion}

Development of bioanalytical method for P-bi-TAT

P-bi-TAT has both hydrophilic (PEG) and lipophilic (triazole tetrac) structures with high affinity for $\alpha v \beta 3$ integrin (Rajabi et al. 2019), resulting in favorable pharmaceutical properties as a targeted anticancer therapeutic. However, it was difficult to develop a quantitative method in MRM in both positive and negative modes because there are multiple molecular weights of P-biTAT and multiple charged ions $(\mathrm{n}=1-5)$ simultaneously formed by ESI. In the positive mode, it shows multiple-

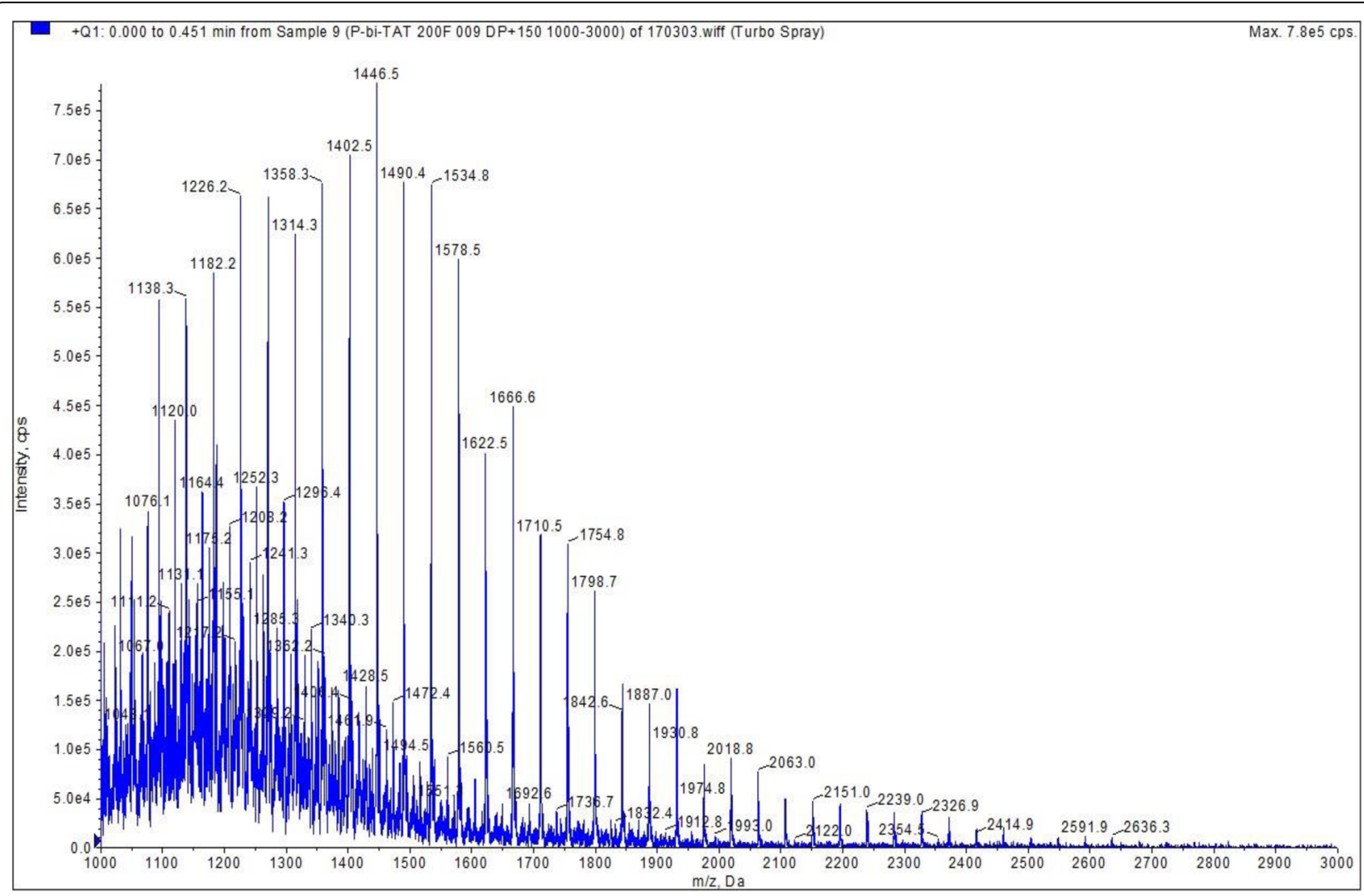

Fig. 4 Full scan mass spectrum (Q1MS) of P-bi-TAT by in-source CID in positive mode 


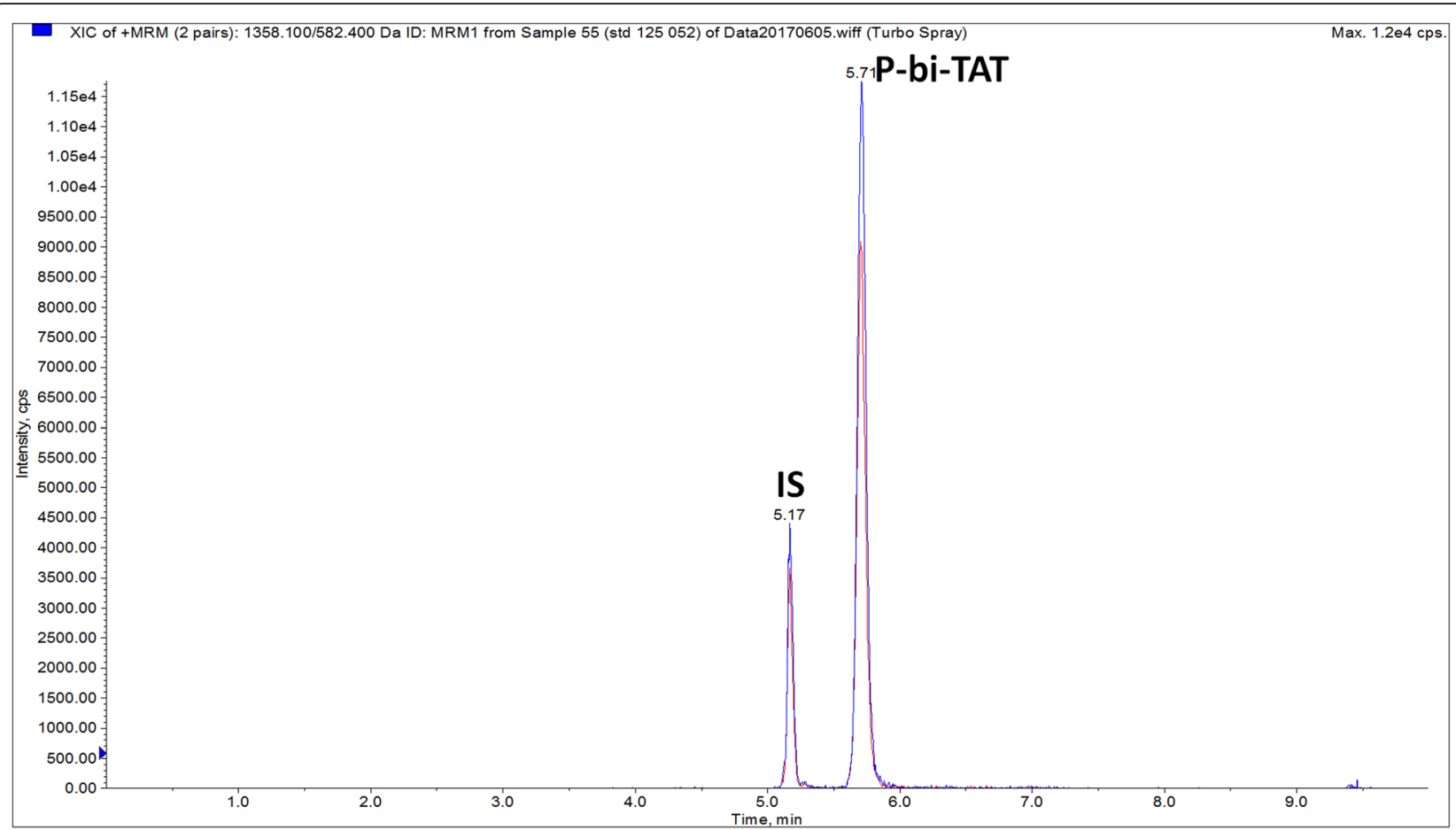

Fig. 5 Typical LC-MS/MS for P-bi-TAT (5.7 min) and IS (5.2 min) in positive mode

charged ions and fragmented ions. Multiple-charged ions are dominant under the low declustering potential (DP, 45 V); however, those ions were too weak as a precursor ion to develop an MRM method. The intensities of fragmented ions showed a maximum under high DP $(\sim 130 \mathrm{~V})$, so we were able to develop the MRM method under those conditions. The LOQ and recovery of the bioanalytical method was satisfactory.

In the negative mode, deprotonated pseudo-molecular ions $[\mathrm{M}-2 \mathrm{H}]^{2-}$ of P-bi-TAT were not strong enough for MRM method development. However, they were useful for calculating the exact mass of individual P-bi-TAT by multiplying $\mathrm{m} / \mathrm{z}$ of the deprotonated ion by $\mathrm{z}$ plus $\mathrm{z}$ $(\mathrm{Mw}=\mathrm{m} / \mathrm{z} \times \mathrm{z}=\mathrm{z})$.

\section{PK and biodistribution of P-bi-TAT in rats and monkeys}

The bioanalytical method was successfully applied to the PK studies in rats and monkeys. Tmax values were the same value of $6 \mathrm{~h}$ in rats and monkeys. The Cmax and AUC values in rats were similar to those in monkeys at low dose. These results of Cmax and AUC suggest that monkeys may be a better model animal than rats for Pbi-TAT, and higher equivalent doses of P-bi-TAT may be required for monkeys (and possibly humans) than for rats to achieve the targeted concentrations in plasma and tissues. Half-lives $\left(T_{1 / 2}\right)$ were longer in monkeys than in rats. Human $T_{1 / 2}$ was estimated to be $49 \mathrm{~h}$ using a simple allometric formula, $Y=\mathrm{a}(\mathrm{Xb})$, where $Y$ is human $T_{1 / 2} ; X$ is rat $T_{1 / 2}$; and $a$ and $b$ are constants
(Sarver et al. 1997). The long half-life in monkeys and possibly in humans suggests the prolonged efficacy of P-bi-TAT as a targeted anticancer treatment (Miyazaki et al. 2021).

The dose ratio between low and high was 3.3 in the monkey study. The results in dose proportionality ratios for Cmax and AUC in the monkey study suggest that the bioavailability of P-bi-TAT is dose-dependent within the dose range administered. Accumulation of P-bi-TAT in target organs and in off-target organs, such as liver and kidney, needs to be investigated further.

The dose-dependent biodistribution of P-bi-TAT in the brain suggests that it is applicable to the therapeutics of brain cancers. Fernandes and coworkers reported that PEGylated caffeic acid and ferulic acid (MW 1000) were permeable across hCMEC/D3 monolayer cells, a model of the blood-brain barrier, by transcellular passive diffusion due to the hydrophobicity (Fernandes et al. 2018). Yang et al. showed that a PEGylated amifostine had cytoprotective effects in vitro (Yang et al. 2016). Fleming et al. reported that the chemotherapy drug Camptothecin conjugated with PEG3400 was delivered into the brain of rats (Fleming et al. 2004). The biodistribution of P-bi-TAT in the brains in the current study may be attributed to the involvement of transthyretin (TTR) and thyroid hormone transporters, such as MCTs and OATPs (Bernal et al. 2015; Horn et al. 2013; Kinne et al. 2010), in addition to passive diffusion because of the high molecular weight of P-bi-TAT (MW > 5000). 
20170609_PBT_STD_002.rdb (PBT): "Linear" Regression ("1 / x" weighting): $y=2.71 x+-0.0979(r=0.9963)$

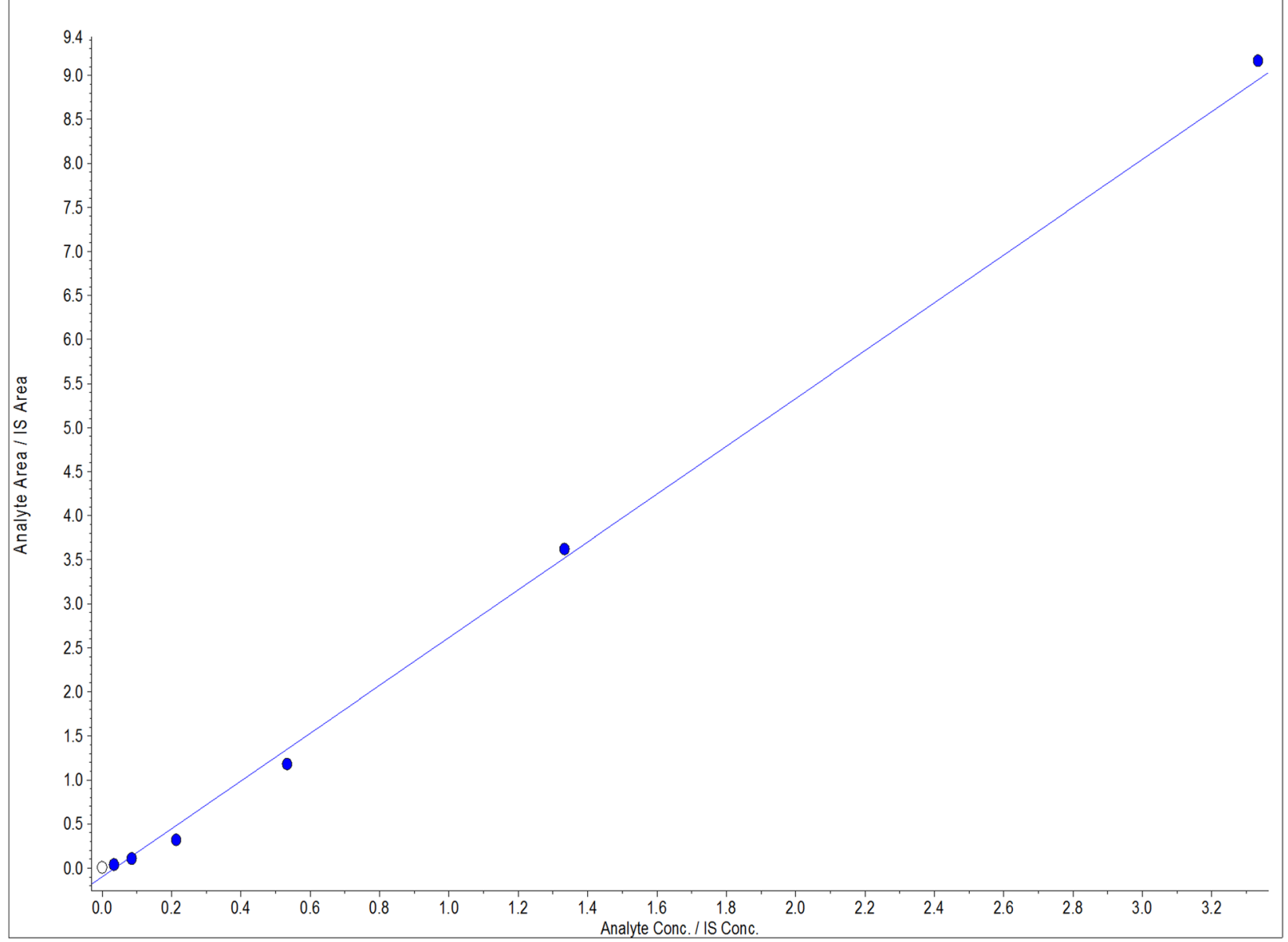

Fig. 6 Standard curve for P-bi-TAT with IS by positive LC-MS/MS

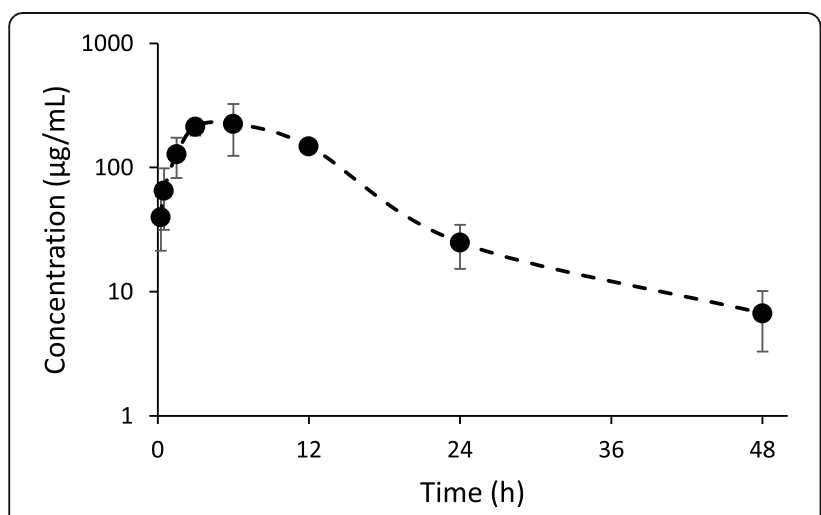

Fig. 7 Time course of plasma levels of P-bi-TAT $(10 \mathrm{mg} / \mathrm{kg})$ in rats $n$ $=4$. Error bars represent standard errors of the mean
Table 1 Parameters in rats $(n=4)$ and monkeys $(n=2$ female and 2 male) dosed with P-bi-TAT

\begin{tabular}{|c|c|c|c|c|}
\hline & Rats & $\begin{array}{l}\text { Monkeys, } \\
\text { low dose }\end{array}$ & $\begin{array}{l}\text { Monkeys, } \\
\text { high dose }^{\neq}\end{array}$ & $\begin{array}{l}\text { Dose } \\
\text { proportionality } \\
\text { ratio }\end{array}$ \\
\hline Tmax (h) & 6 & 6 & 7 & - \\
\hline $\mathrm{Cmax}(\mu \mathrm{g} / \mathrm{mL})$ & 225 & 222 & 727 & 3.3 \\
\hline M/F ratio, Cmax & - & 1.1 & 1.0 & - \\
\hline $\mathrm{T}_{1 / 2}(\mathrm{~h})$ & 8.1 & 19.2 & 14.5 & - \\
\hline $\operatorname{A\cup C}\left(\mu \mathrm{g} / \mathrm{mL}^{*} h\right)$ & 3564 & 3649 & 11733 & 3.2 \\
\hline M/F ratio, AUC & - & 1.2 & 1.3 & - \\
\hline
\end{tabular}

${ }^{\dagger}$ Low dose, $25 \mathrm{mg} / \mathrm{kg}$ body weight

${ }^{\text {F}}$ High dose, $82.5 \mathrm{mg} / \mathrm{kg}$

$\mathrm{M} / \mathrm{F}$ ratio $(\mathrm{AUC})=$ male/female 


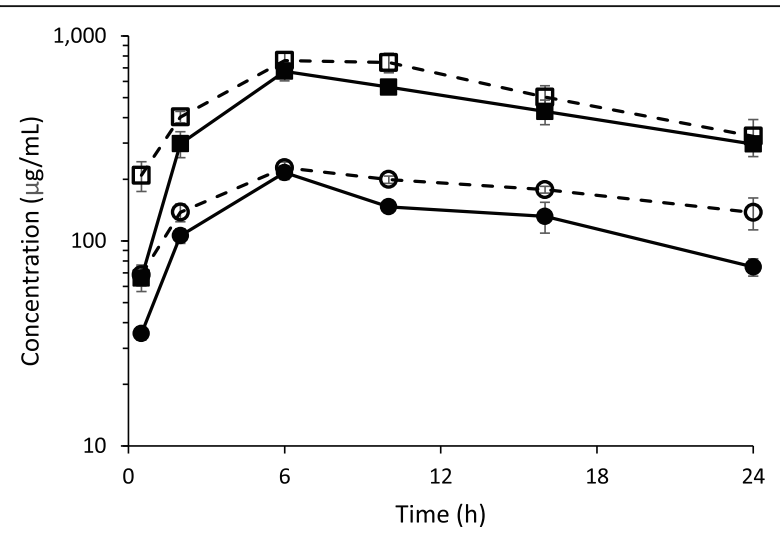

Fig. 8 Time courses of plasma levels of P-bi-TAT in monkeys on day 1 and day $7, n=2$ for female and $n=2$ for males. Low dose $25 \mathrm{mg} / \mathrm{kg}$ body weight, high dose $82.5 \mathrm{mg} / \mathrm{kg}$ body weight. Error bars represent standard errors of the mean. Day 1, low dose: closed circles; day 7, low dose: open circles; day 1, high dose: closed squares; day 7 , high dose: open squares

\section{Conclusion}

The PK parameters and biodistribution of P-bi-TAT in rats and monkeys showed its preferable characteristics as a targeted anticancer pharmaceutical. A quantitative bioanalytical method for P-bi-TAT was developed using LC-MS/MS and SPE. P-bi-TAT showed the strongest MRM intensity in the positive mode under ion-source CID conditions. The LOQ for P-bi-TAT was $30 \mathrm{ng} / \mu \mathrm{L}$ and the recovery efficiency was $76 \%$. The bioanalytical method was applied to PK studies of P-bi-TAT and results suggest that P-bi-TAT is a promising candidate as a targeted anticancer drug. Its efficacies on multiple cancer types, accumulation in organs, toxicokinetic, and pharmacodynamics need to be further investigated.

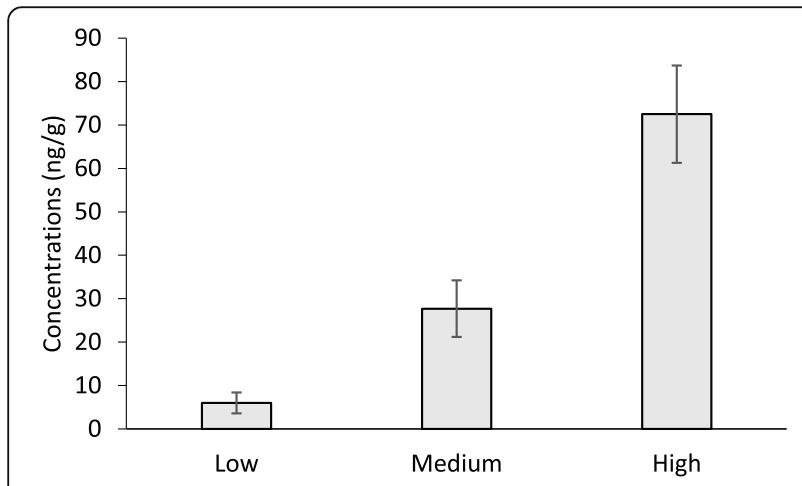

Fig. 9 P-bi-TAT levels in the brain of rats $(n=4)$ at low $(1 \mathrm{mg} / \mathrm{kg})$, medium (3 mg/kg), and high (10 mg/kg) doses. Error bars represent standard errors of the mean

\section{Acknowledgements}

Special thanks to both NanoPharmaceuticals LLC and from the Pharmaceutical Research Institute for their funding. Special thanks to PRI chemists and biologists for their teamwork.

\section{Authors' contributions}

Kazutoshi Fujioka contributed to the analytical and bioanalytical method development, validation, and drafted the manuscript; Kavitha Godugu contributed to the animal studies for PK and biodistribution; and Shaker A. Mousa contributed the study design, concepts, data review, supervision, and edits of the manuscript. The authors read and approved the final manuscript.

\section{Funding}

Funding was received from both NanoPharmaceuticals LLC and from the Pharmaceutical Research Institute at Albany College of Pharmacy and Health Sciences.

\section{Availability of data and materials}

All data are available and stored at Pharmaceutical Research Institute (PRI)intranet. All materials related to the project are available at PRI laboratories.

\section{Declarations}

\section{Competing interests}

S.A. Mousa has a patent related to P-bi-TAT and he is a founder of NanoPharmaceuticals LLC, which is developing anticancer drugs. All other authors declare no conflicts of interest.

Received: 5 May 2021 Accepted: 7 July 2021

Published online: 16 August 2021

\section{References}

Anthony C, Mladkova-Suchy N, Adamson DC (2019) The evolving role of antiangiogenic therapies in glioblastoma multiforme: current clinical significance and future potential. Expert Opin Investig Drugs 28(9):787-797. https://doi.org/10.1080/13543784.2019.1650019

Bernal J, Guadaño-Ferraz A, Morte B (2015) Thyroid hormone transporters-functions and clinical implications. Nat Rev Endocrinol 11(7):406-417. https:// doi.org/10.1038/nrendo.2015.66

Fernandes C, Pinto M, Martins C, Gomes MJ, Sarmento B, Oliveira PJ, Remião F, Borges F (2018) Development of a PEGylated-based platform for efficient delivery of dietary antioxidants across the blood-brain barrier. Bioconjug Chem 29(5):1677-1689. https://doi.org/10.1021/acs.bioconjchem.8b00151

Fleming AB, Haverstick K, Saltzman WM (2004) In vitro cytotoxicity and in vivo distribution after direct delivery of PEG-camptothecin conjugates to the rat brain. Bioconjug Chem 15(6):1364-1375. https://doi.org/10.1021/bc034180o

Fox BM, Janssen A, Estevez-Ordonez D, Gessler F, Vicario N, Chagoya G, Elsayed G, Sotoudeh H, Stetler W, Friedman GK, Bernstock JD (2019) SUMOylation in glioblastoma: a novel therapeutic target. Int J Mol Sci 20(8):1853. https://doi. org/10.3390/ijms20081853

Henley SJ, Ward EM, Scott S, Ma J, Anderson RN, Firth AU, Thomas CC, Islami F, Weir HK, Lewis DR, Sherman RL, Wu M, Benard VB, Richardson LC, Jemal A, Cronin K, Kohler BA (2020) Annual report to the nation on the status of cancer, part I: National cancer statistics. Cancer 126(10):2225-2249. https:// doi.org/10.1002/cncr.32802

Horn S, Kersseboom S, Mayerl S, Müller J, Groba C, Trajkovic-Arsic M, Ackermann T, Visser TJ, Heuer H (2013) Tetrac can replace thyroid hormone during brain development in mouse mutants deficient in the thyroid hormone transporter mct8. Endocrinology 154(2):968-979. https://doi.org/10.1210/en.2 012-1628

Kinne A, Kleinau G, Hoefig CS, Grüters A, Köhrle J, Krause G, Schweizer U (2010) Essential molecular determinants for thyroid hormone transport and first structural implications for monocarboxylate transporter 8. J Biol Chem 285(36):28054-28063. https://doi.org/10.1074/jbc.M1 10.129577

Laquintana V, Trapani A, Denora N, Wang F, Gallo JM, Trapani G (2009) New strategies to deliver anticancer drugs to brain tumors. Expert Opin Drug Deliv 6(10):1017-1032. https://doi.org/10.1517/17425240903167942

Le Rhun E, Preusser M, Roth P, Reardon DA, van den Bent M, Wen P, Reifenberger G, Weller M (2019) Molecular targeted therapy of glioblastoma. Cancer Treat Rev 80:101896. https://doi.org/10.1016/j.ctrv.2019.101896 
Lin HY, Chin YT, Nana AW, Shih YJ, Lai HY, Tang HY, Leinung M, Mousa SA, Davis PJ (2016) Actions of I-thyroxine and nano-diamino-tetrac (Nanotetrac) on PDL1 in cancer cells. Steroids. 114:59-67. https://doi.org/10.1016/j.steroids.2016. 05.006

Lin SJ, Chin YT, Ho Y, Chou SY, Sh Yang YC, Nana AW, Su KW, Lim YT, Wang K, Lee SY, Shih YJ, Chen YR, Whang-Peng J, Davis PJ, Lin HY, Fu E (2018) Nanodiamino-tetrac (NDAT) inhibits PD-L1 expression which is essential for proliferation in oral cancer cells. Food Chem Toxicol 120:1-11

Maeda H, Tsukigawa K, Fang J (2016) A retrospective 30 years after discovery of the enhanced permeability and retention effect of solid tumors: nextgeneration chemotherapeutics and photodynamic therapy--problems, solutions, and prospects. Microcirculation 23(3):173-182. https://doi.org/1 $0.1111 /$ micc. 12228

Miyazaki T, Maiti M, Hennessy M, Chang T, Kuo P, Addepalli M, Obalapur P, Sheibani S, Wilczek J, Pena R, Quach P, Cetz J, Moffett A, Tang Y, Kirk P, Huang J, Sheng D, Zhang P, Rubas W, Madakamutil L, Kivimäe S, Zalevsky J (2021) NKTR-255, a novel polymer-conjugated rhlL-15 with potent antitumor efficacy. J Immunother Cancer 9(5):e002024. https://doi.org/10.1136/jitc-2020002024

Rajabi M, Godugu K, Sudha T, Bharali DJ, Mousa SA (2019) Triazole modified tetraiodothyroacetic acid conjugated to polyethylene glycol: high affinity thyrointegrin av $\beta 3$ antagonist with potent anticancer activities in glioblastoma multiforme. Bioconjug Chem 30(12):3087-3097. https://doi. org/10.1021/acs.bioconjchem.9b00742

Sarver JG, White D, Erhardt P, Bachmann K (1997) Estimating xenobiotic half-lives in humans from rat data: influence of log P. Environ Health Perspect 105(11): 1204-1209. https://doi.org/10.1289/ehp.971051204

Sudha T, Bharali DJ, Sell S, Darwish NHE, Davis PJ, Mousa SA (2017a) Nanoparticulate tetrac inhibits growth and vascularity of glioblastoma xenografts. Horm Cancer 8(3):157-165. https://doi.org/10.1007/s12672-01 7-0293-6

Sudha T, Bharali DJ, Yalcin M, Darwish NH, Coskun MD, Keating KA, Lin HY, Davis PJ, Mousa SA (2017b) Targeted delivery of cisplatin to tumor xenografts via the nanoparticle component of nano-diamino-tetrac. Nanomedicine (London) 12(3):195-205. https://doi.org/10.2217/nnm-2016-0315

Warrack BM, Redding BP, Chen G, Bolgar MS (2013) Determination of the molecular weight of poly(ethylene glycol) in biological samples by reversedphase LC-MS with in-source fragmentation. Anal Bioanal Chem 405(12):42834287. https://doi.org/10.1007/s00216-013-6795-3

Xu J, Murphy SL, Kockanek KD, Arias E (2020) Mortality in the United States, 2018. NCHS Data Brief 355:1-8

Yang X, Ding Y, Ji T, Zhao X, Wang H, Zhao X, Zhao R, Wei J, Qi S, Nie G (2016) Improvement of the in vitro safety profile and cytoprotective efficacy of amifostine against chemotherapy by PEGylation strategy. Biochem Pharmacol 108:11-21. https://doi.org/10.1016/j.bcp.2016.02.014

Yin L, Ren T, Zhao S, Shi M, Gu J (2020) Comparative pharmacokinetic study of PEGylated gemcitabine and gemcitabine in rats by LC-MS/MS coupled with pre-column derivatization and MSALL technique. Talanta 206:120184. https://doi.org/10.1016/j.talanta.2019.120184

\section{Publisher's Note}

Springer Nature remains neutral with regard to jurisdictional claims in published maps and institutional affiliations.

\section{Submit your manuscript to a SpringerOpen ${ }^{\circ}$ journal and benefit from:}

- Convenient online submission

- Rigorous peer review

- Open access: articles freely available online

- High visibility within the field

- Retaining the copyright to your article

Submit your next manuscript at $\boldsymbol{\nabla}$ springeropen.com 